\title{
Chronic post-traumatic stress in mothers of very low birth weight preterm infants born before 32 weeks of gestation
}

\author{
Diana C. Rodriguez, M.D. ${ }^{a, c}$, José M. Ceriani-Cernadas, M.D. ${ }^{a, c, d}$, Paz Abarca, B.S. ${ }^{b}$, \\ Eleonora Edwards, B.S. ${ }^{b, c}$, Luciana Barrueco, ${ }^{\text {B.S.b }}$, Pedro Lesta, M.D. ${ }^{b}$ and Pablo Durán, M.D. ${ }^{e}$
}

a. Division of Neonatology, Department of Pediatrics, Hospital Italiano de Buenos Aires, Argentina.

b. Division of Pediatric Mental Health, Department of Pediatrics, Hospital Italiano de Buenos Aires, Argentina.

c. School of Medicine, Instituto Universitario del Hospital Italiano de Buenos Aires, Argentina.

d. Council of Publications of the Argentine Society of Pediatrics.

e. Latin American Center for Perinatology, PAHO. Montevideo, Uruguay.

E-mail address:

José M. Ceriani Cernadas: jose.ceriani@

hospitalitaliano.org.ar

Funding:

None.

Conflict of interest:

None.

Received: 1-21-2020

Accepted: 4-13-2020

\section{ABSTRACT}

Background. The birth of very low birth weight (VLBW) preterm infants causes stress in mothers, which may continue for over 6 months. This is called chronic post-traumatic stress disorder (CPTSD).

Objective. To detect CPTSD frequency and symptoms among mothers of VLBW preterm infants born before 32 weeks of gestation.

Methods. Cross-sectional cohort study in mothers using a survey based on the Davidson Trauma Scale.

Results. A total of 172 surveys were administered but 146 were included; $82(56 \%)$ did not have stress symptoms, while $64(44 \%)$ had CPTSD. Mothers with CPTSD accounted for $46.8 \%$ of preterm infants born at $\leq 28$ weeks versus $31.7 \%$ in those without CPTSD $(p=0.032)$. Preterm infants with a birth weight $<1000 \mathrm{~g}$ were significantly more frequent among mothers with CPTSD, $53 \%$ versus $34 \%$ among those without stress $(p=0.011)$.

No differences were observed in neonatal morbidity $(p=0.072)$. Severe morbidity in preterm infants was significantly more common among those with CPTSD, $43.8 \%$ versus $28 \%$ $(p \leq 0.004)$.Mothers who had a lower education accounted significantly for more cases of CPTSD $(p=0.013)$. No significant differences were seen in maternal age $(p=0.313)$, children's age $(p=0.405)$, and length of stay $(p=0.316)$.

Conclusion. Among the mothers of VLBW preterm infants, $44 \%$ had CPTSD, and this was significantly more common among those who had preterm infants born at $\leq 28$ weeks, a birth weight $<1000 \mathrm{~g}$, severe morbidity, and a lower level of education.

Key words: preterm infants, mothers, chronic posttraumatic stress, symptoms.

http:/ / dx.doi.org/10.5546/aap.2020.eng.306

To cite: Rodríguez DC, Ceriani Cernadas JM, Abarca P, Edwards E, et al. Chronic post-traumatic stress in mothers of very low birth weight preterm infants born before 32 weeks of gestation. Arch Argent Pediatr 2020;118(5):306-312.

\section{INTRODUCTION}

The birth of a very low birth weight preterm infant is usually an unexpected event that leads to different somatic and psychological disorders, which may cause stress and depression symptoms. These are some of the most commonly observed, documented in several studies. ${ }^{1-4}$ This is important because a traumatic parental experience at the NICU may linger over time. According to the Diagnostic and Statistical Manual of Mental Disorders, fourth edition (DSM-IV), Post-Traumatic Stress Disorder (PTSD) is classified under the anxiety disorders category, and is the result of the exposure to a traumatic event. ${ }^{5-7}$

Three types of symptoms are usually present in PTSD: experiencing a traumatic event, avoiding things that remind of the event and/or psychological blunting. These symptoms are persistent and present in an increased alertness state, with autonomic activation when faced with different situations. ${ }^{8-12}$

According to the DSM-IV, when stress symptoms persists after the first 6 months of the traumatic event, it is defined as chronic posttraumatic stress disorder (CPTSD). Several factors are involved in CPTSD associated with prematurity, ${ }^{12-20}$ including an unexpected preterm birth, grief over the term birth and the baby that the parents had imagined, a profound anguish over the potential death of the baby, concern about the baby requiring invasive therapies; barriers that hurdle early interactions with the baby at the NICU and inability to breastfeed. Likewise, notable changes in parents' lifestyle 
during the baby's hospitalization (daily contact with other children and family), concerns and worries about hospital readmission ${ }^{20}$ and potential future medical conditions.

Primary objective: to determine the frequency and characteristics of CPTSD symptoms in the mothers of VLBW preterm infants born before 32 weeks of gestation for more than 6 months and up to 5 years after birth.

Secondary objective: to assess the results of the survey outcome measures among mothers with and without CPTSD.

\section{METHODS}

The study started on March 3, 2014 and ended on November 22, 2016.

Design: prospective, cross-sectional study in a cohort of mothers who attended follow-up visits with their VLBW preterm infants born before 32 weeks of gestation. The study was carried out at the Preterm Infant Follow-up Clinic of the Division of Neonatology and the Division of Pediatric Mental Health of the Department of Pediatrics of Hospital Italiano de Buenos Aires, Argentina. Data were collected using a selfadministered voluntary survey completed by the mothers of preterm infants. Surveys were given by 2 psychologists from the follow-up team, in order to provide mothers with any support they could have needed. The surveys were completed at the VLBW Preterm Infant Follow-up Clinic or sent by e-mail.

Inclusion criteria: mothers with singleton pregnancies who had VLBW preterm infants born before 32 weeks of gestation and admitted to the Preterm Infant Follow-up Program, and who gave their informed consent. At the time of the survey, children were aged 6 months to 5 years.

Exclusion criteria: mothers with psychiatric disorders before and/or during gestation, newborn infants with chronic conditions after hospital discharge, and those with congenital malformations and diseases. Incomplete surveys and refusal to give the informed consent were also excluded.

The study was approved by the Ethics Committee of the Hospital Italiano de Buenos Aires.

\section{Primary outcome variable}

Frequency of mothers of VLBW preterm infants born before 32 weeks who had CPTSD symptoms.

\section{Secondary outcome variables}

Description of maternal CPTSD symptoms

Maternal age: $\leq 21$ years, 22-26 years, 27 -

31 years, 32-36 years, $37-41$ years, and $\geq 42$ years.

Level of maternal education.

Gestational age: $\leq 28$ weeks and between

29 and 31.6 weeks.

Birth weight: $\leq 1000 \mathrm{~g}$ and between 1000 and $1490 \mathrm{~g}$.

Neonatal morbidity (mild, moderate, and severe).

Length of stay (days) of preterm infants at the NICU.

Age (months and years) of children of mothers with and without CPTSD.

\section{Instrument}

The Davidson Trauma Scale (DTS) ${ }^{21}$ was used, which has been designed to score the frequency and severity of CPTS symptoms in people who have experienced a stressful event (see Annex). The scale's items are based on the DSM-IV criteria (criterion B, items 1-4 and 17; criterion C, items 5-11; and criterion D, items 12-16). The DTS includes 17 items; those related to intrusion and avoidance, refer to the stressful event, whereas those related to blunting, isolation, and hyper-arousal only score with their presence or absence. Each item is rated through a double scale: frequency and severity. According to the DTS, the 7 days prior to the time of the survey were taken as the reference framework. The DTS has been validated in the Anglo-Saxon population and translated and validated in Spain by Bobes, et al. ${ }^{22}$ and this is the version we used in our study.

Instrument testing and validation. The DTS had not been validated in Argentina, so we initially performed a validation to test the instrument and assess its reliability with a sample of 30 surveys administered to the study population. In addition, we assessed the interobserver consistency by having the survey administered by 2 independent observers in each case. The investigators and external observers assessed the instrument's validation by reviewing and analyzing it. Data consistency was assessed based on the frequency distribution of each outcome measure.

\section{Definitions}

Severe neonatal morbidity: hyaline membrane disease (HMD) requiring mechanical ventilation for more than 72 hours and 1 or 2 surfactant doses; grade $3 / 4$ intracranial 
hemorrhage (ICH); periventricular leukomalacia; severe bronchopulmonary dysplasia (BPD); shock of any etiology; confirmed sepsis, either early or late; meningitis; grade II/ III necrotizing enterocolitis (NEC); hyperbilirubinemia over the $90^{\text {th }}$ percentile requiring phototherapy for more than 5 days and / or exchange transfusion; retinopathy of prematurity (ROP) requiring laser therapy; symptomatic patent ductus arteriosus requiring surgery.

Moderate neonatal morbidity: $\mathrm{HMD}$ requiring CPAP and 1 surfactant dose; grade $1 / 2 \mathrm{ICH}$; grade Ib NEC; moderate BPD; very probable sepsis; bilirubin levels between the $75^{\text {th }}$ and $90^{\text {th }}$ percentiles requiring phototherapy for more than 72 hours; grade II ROP or higher that did not require treatment; symptomatic patent ductus arteriosus requiring drug treatment.

Mild neonatal morbidity: mild HMD or transient respiratory distress only requiring oxygen through a mask or hood at not more than $30 \%$; grade Ia NEC; hyperbilirubinemia requiring phototherapy for less than 72 hours.

\section{Statistical analysis}

For a probable CPTS syndrome frequency of $25 \%$, with an estimation error of $5 \%$, a $95 \%$ confidence interval (CI), and a $20 \%$ loss, the sample was estimated at 170 mothers.

For each of the outcome measures, a descriptive data analysis was performed using mean, standard deviation, median, minimum and maximum values for continuous outcome measures, and frequency and percentage for discrete and qualitative ones.

The assumption of normality was verified using the Shapiro-Wilk test. The differences between the 2 independent groups were established using the Mann-Whitney test, or the Kruskal-Wallis test when more than

TABLE 1. Frequency of maternal CPTSD by children's age

\begin{tabular}{ccc}
\hline $\begin{array}{c}\text { Age } \\
\text { (months old) }\end{array}$ & $\begin{array}{c}\text { Answers } \\
\mathbf{N}(\%)\end{array}$ & $\begin{array}{c}\text { CPTSD } \\
\mathbf{N}(\%)\end{array}$ \\
\hline $7-12$ & $61(41.7)$ & $23(36.2)$ \\
$13-18$ & $25(17.2)$ & $11(17.4)$ \\
$19-24$ & $17(11.7)$ & $9(14)$ \\
$25-36$ & $17(11.7)$ & $9(14)$ \\
$>36$ & $26(17.7)$ & $12(18.4)$ \\
\hline Total & $146(100)$ & $64(100)$ \\
\hline
\end{tabular}

CPTSD: chronic post-traumatic stress disorder.
2 independent groups were compared. The difference of two proportions was used to compare percentage values. A logistic regression model was used in the presence of CPTSD in relation to the level of maternal education.

In all cases, a $p<0.05$ difference was considered statistically significant.

The SPSS statistical software, version 22, was used for data analysis.

\section{RESULTS}

The surveys were administered to 172 mothers; 26 were excluded because they were incomplete and 146 were included for assessment. A total of 34 mothers completed the survey by e-mail and the rest did it in person when they attended the Follow-up Clinic for the control of their infants. Out of all answers, $82(56 \%)$ did not have CPTSD symptoms and $64(44 \%)$ had symptomatic stress 6 months after their baby's birth. CPTSD was more common among mothers of infants aged 7-12 months $(37.5 \%)$ and it lasted for several years, including $18.7 \%$ of those who continued with CPTSD symptoms between 3 and 5 years after birth (Table 1). Based on mothers' age, those who were $27-31$ years $(54.3 \%)$ showed the higher CPTSD frequency (Table 2).

The three most common CPTSD symptoms were painful images and memories of the event $(59 \%)$, increased nervousness (51\%), and irritability with frequent anger out bursts $(48 \%)$ (Table 3). Mothers with CPTSD accounted for $46.8 \%$ of preterm infants born at $\leq 28$ weeks versus $31.7 \%$ in mothers without CPTSD $(p=0.032$, relative risk [RR]: 0.9801-2.2299), which was a significant difference (Table 4), and they accounted for $53 \%$ of those born between 29 and 31.5 weeks versus $68 \%$ among mothers without CPTSD. Preterm infants with a birth weight $<1000 \mathrm{~g}$ were significantly more frequent

TABLE 2. Frequency of CPTSD by maternal age

\begin{tabular}{ccc}
\hline $\begin{array}{c}\text { Maternal age } \\
\text { (years old) }\end{array}$ & $\begin{array}{c}\text { Answers } \\
\text { N (\%) }\end{array}$ & $\begin{array}{c}\text { CPTSD } \\
\text { N (\%) }\end{array}$ \\
\hline$\leq 21$ & $5(3.4)$ & $2(3.1)$ \\
$22-26$ & $8(5.4)$ & $4(6.25)$ \\
$27-31$ & $35(24)$ & $19(29.7)$ \\
$32-36$ & $51(35)$ & $17(26.6)$ \\
$37-41$ & $35(24)$ & $18(28.1)$ \\
$\geq 42$ & $12(8.2)$ & $4(6.25)$ \\
\hline Totales & $146(100)$ & $64(100)$ \\
\hline
\end{tabular}

CPTSD: chronic post-traumatic stress disorder. 
among mothers with CPTSD $(53 \%)$ versus those without stress $(34 \%)$ ( $p=0.011$, RR: $1.0117-$ 2.2718) (Table 5). No significant differences were observed in terms of neonatal morbidity, although a tendency was noted $(p=0.072)$. Severe morbidity was significantly more common in the preterm infants of mothers with CPTSD versus those without stress, $44 \%$ and $27 \%$, respectively $(p=0.0048)$ (Table 6). Mothers with CPTSD had a significantly lower level of education, $95 \%$ CI: 15.5 [7-19] versus 17.5 [10-18, $p=0.0133)$. The logistic regression showed an odds ratio of 0.871 with a $p$ value of 0.026 , and a $95 \%$ CI between 0.771 and 0.984 . No significant differences were observed in relation to the other outcome measures: maternal age (RR: 50 [24-140], $p=0.313$ ), children's age (RR: 17 [6-58], $p=0.405)$, and length of stay in the NICU (RR: 50 [24-140], $p=0.316$ ).

\section{DISCUSSION}

In this study, we observed that a high percentage of mothers of VLBW preterm infants born before 32 weeks of gestation developed symptoms that met the DSM-IV criteria for

TABLE 3. Symptoms and frequency in mothers with CPTSD

\begin{tabular}{lc}
\hline & Frequency \\
\hline Painful images and memories of the event & $59 \%$ \\
Usually very nervous & $51 \%$ \\
Irritable or outbursts of anger & $48 \%$ \\
Very easily scared & $47 \%$ \\
Poor concentration & $43 \%$ \\
Difficulty enjoying things, irritability & $33 \%$ \\
Discomfort because of something you remember & $33 \%$ \\
Trouble falling asleep or staying asleep & $30 \%$ \\
Avoiding thoughts or feelings & $29 \%$ \\
Feeling distant or cut off from other people & $25 \%$ \\
Unable to imagine a long life & $19 \%$ \\
Avoiding doing things or going into situations which remind you about the traumatic event & $15 \%$ \\
Feeling as though the event was re-occurring & $15 \%$ \\
Inability to recall important parts of the event & $14 \%$ \\
Physically upset by reminders of the event & $13 \%$ \\
Inability to have sad feelings & $11 \%$ \\
Distressing dreams of the event & $8 \%$ \\
\hline
\end{tabular}

CPTSD: chronic post-traumatic stress disorder.

TABLE 4. Gestational age of preterm infants of mothers with and without CPTSD

\begin{tabular}{lccc}
\hline & $\mathbf{2 9 - 3 1 . 6}$ weeks & $\mathbf{2 2 8 \text { weeks }}$ & Total \\
& $\mathbf{N}(\boldsymbol{\%})$ & $\mathbf{N}(\boldsymbol{\%})$ & $\mathbf{N}(\%)$ \\
\hline With CPTSD & $30(34.8)$ & $34(56.6)$ & $64(43.9)$ \\
Without CPTSD & $56(65.2)$ & $26(43.4)$ & $82(56.1)$ \\
& 86 & 60 & $146(100)$ \\
\hline
\end{tabular}

CPTSD: chronic post-traumatic stress disorder.

Gestational age equal to or less than 28 weeks: $p=0.032$.

TABLE 5. Birth weight of preterm infants of mothers with and without CPTSD

\begin{tabular}{|c|c|c|c|}
\hline & $\begin{array}{c}\text { Weight } \\
1000 \mathrm{~g}-1490 \mathrm{~g} \\
\mathrm{~N}(\%)\end{array}$ & $\begin{array}{c}\text { Weight } \\
<1000 \mathrm{~g} \\
\mathrm{~N}(\%)\end{array}$ & $\begin{array}{l}\text { Total } \\
\text { N (\%) }\end{array}$ \\
\hline With CPTSD & $30(35.7)$ & $34(54.8)$ & $64(43.9)$ \\
\hline Without CPTSD & $\begin{array}{c}54(64.3) \\
84\end{array}$ & $\begin{array}{c}28(34) \\
62\end{array}$ & $\begin{array}{l}82(56.1) \\
146(100)\end{array}$ \\
\hline
\end{tabular}

CPTSD: chronic post-traumatic stress disorder.

Weight less than $1000 \mathrm{~g}: \mathrm{p}=0.011$. 
PTSD. Such frequency was higher than what has been reported in the studies published to date. According to the DSM-IV based on published studies and criteria, the frequency in the general population ranges from $1 \%$ to $14 \%$. In the studies conducted in individuals at risk, war veterans, and terrorist attack victims, it ranged from $3 \%$ to $58 \%$.

Likewise, few publications have pointed out the prevalence of CPTSD in populations similar to the one included in our study $9,13,14$

Some studies have focused on symptoms but were limited in their results because of methodological weaknesses or because they did not include the complete syndrome. One study estimated a $23 \%$ prevalence in mothers of VLBW newborns who had CPTSD 6 months after discharge from the NICU $1,2,7,13$.

Our experience in the Follow-up Program for Preterm Infants with a birth weight $<1500 \mathrm{~g}$ at the Division of Neonatology of Hospital Italiano de Buenos Aires started more than 40 years ago. In this period, we have observed different symptoms in the mothers that may have CPTSD, who described more frequently symptoms such as getting very "nervous" when taking their babies to the hospital, usually having difficulty to enjoy everyday activities, avoiding memories of what happened during childbirth and at the NICU, difficulty sleeping and waking up several times during the night, not daring to visit the NICU to say hi to the physicians and nurses, even though some expressed their eternal gratitude to them, and referred a severe psychological distress when remembering the traumatic events at the NICU, the pain and the unexpected preterm birth, anguish over the potential death of the baby, and not wanting to look at the pictures of the baby at the NICU.

Similarly, several mothers pointed out that during the length of stay of their babies at the NICU they were already stressed, and frequently described it as severe stress. Different published studies have described the perceptions of parents about the aspects that made the stay at the NICU very stressful. ${ }^{1-5}$ The stress levels in NICU mothers may be reduced through an early intervention such as the use of screening tool to detect the presence of stress even from the first days since admission. In our study, we used the Parental Stressor Scale: Neonatal Intensive Care Unit (PSS: NICU) and the Beck Depression Inventory (BDI), which allowed us to intervene and thus reduce stress. ${ }^{3,4}$

Both in our experience and in other studies, ${ }^{8-11}$ a stress reduction was achieved before hospital discharge. Such intervention measures at the NICU may possibly reduce CPTSD. For some mothers, most stress symptoms will disappear over the first months, but if they linger for more than 6 months and becomes a chronic issue, this is due to the traumatic events initially generated by the unexpected preterm delivery. The DSMIV definitions point out that a traumatic event may result from death situations affecting an individual's physical integrity, in this case, VLBW preterm infants, who mostly have disorders of varying severity, including death. This event leads the individuals, in this case, the parents, towards feelings of fear and despair. These aspects are probably more common because very small preterm infants remain at the NICU for weeks or months, and this means a very stressful situation for the parents.

In addition, it is worth noting that offering different treatments to mothers can most likely help them achieve emotional well-being, selfconfidence, and other psychosocial factors that are very important requirements for an adequate, long-term course in their preterm infants. ${ }^{24} \mathrm{We}$ believe that the early detection of PTSD may be relevant for the future development of the child.

Some studies assessed the use of psychological therapy in individuals who experienced

TABLE 6. Morbidity in preterm infants of mothers with and without CPTSD

\begin{tabular}{|c|c|c|c|c|c|c|c|c|}
\hline & \multicolumn{2}{|c|}{ Mild } & \multicolumn{2}{|c|}{ Moderate } & \multicolumn{2}{|c|}{ Severe } & \multicolumn{2}{|c|}{ Total } \\
\hline & $\mathbf{N}$ & $\%$ & $\mathbf{N}$ & $\%$ & $\mathbf{N}$ & $\%$ & $\mathbf{N}$ & $(\%)$ \\
\hline With CPTSD & 21 & $(39.7)$ & 15 & $(34.0)$ & 28 & $(57.1)$ & 64 & (43.8) \\
\hline Without CPTSD & 32 & $(60.3)$ & 29 & $(66.0)$ & 21 & $(42.9)$ & 82 & $(56.2)$ \\
\hline $\mathrm{N}$ & 53 & (100) & 44 & (100) & 49 & (100) & 146 & (100) \\
\hline
\end{tabular}

CPTSD: chronic post-traumatic stress disorder.

Morbidity throughout the group: $\mathrm{p}=0.072$.

Severe morbidity in neonates $<1000 \mathrm{~g}$ : $\mathrm{p}=0.004$. 
a traumatic event leading to severe stress accompanied by different distress factors.

Results were similar or even better than medication with antidepressants to reduce the symptoms of post-traumatic stress. Experiences in soldiers who went to war and other circumstances showed that psychological therapy would be better than long-term exposure to drugs and other resources. ${ }^{24,25}$

\section{Limitations}

Our study has evident limitations, such as not including a more detailed assessment of the predictors of CPTSD symptoms in the mothers, not detecting support from family and close friends, we did not adequately assess mothers who maintained stress between 3 to 5 years, nor assessing whether parents had consulted a religious advisor or if they practiced any religion.

\section{CONCLUSIONS}

This cohort study allowed us to assess the frequency of CPTSD and its symptoms in mothers of VLBW preterm infants born before 32 weeks of gestation. Mothers showed a high prevalence of CPTSD symptoms (44\%). Among studied outcome measures, gestational age, birth weight, severe neonatal morbidity, and a lower level of maternal education were significantly more common among the mothers with CPTSD compared to those without CPTSD. Likewise, it is worth noting that maternal CPTSD symptoms lasted for several years after the birth of the babies, and some mothers even continued experiencing stress 3 to 5 years after birth.

\section{Acknowlegdment}

We thank Dr. Laura Konikoff for her very kind collaboration in translating the manuscript and Dr. Pablo Brener for his collaborations in the revision of the manuscript. Likewise, we thank Lic. Mirian Nuñes who kindly performed the statistical analysis.

\section{REFERENCES}

1. Ruiz AL, Cravedi V, Ceriani Cernadas JM. Stress and depression in mothers of premature infants: Evaluation of a psychosocial intervention model in the NICU, a randomized controlled study. Pediatr Res. 1999;222(45):A1303.

2. Ruiz AL, Ceriani Cernadas JM, Cravedi V, Rodríguez D. Estrés y depresión en madres de prematuros, un programa de intervención. Arch Argent Pediatr. 2005;103(1):36-45.

3. Shields-PoëDS, Pinelli J. Variables associated with parental stress in neonatal intensive care units. Neonatal Netw. 1997;16(1):29-37.

4. Helle N, Barkmann C, Ehrhardt S, Bindt C. Postpartum posttraumatic and acute stress in mothers and fathers of infants with very low birth weight: Cross-sectional results from a controlled multicenter cohort study. J Affect Disord. 2018;235:467-73.

5. Lefkowitz D, BaxtC, Evans JR. Prevalence and correlates of posttraumatic stress and postpartum depression in parents of infants in the neonatal intensive care unit (NICU). J Clin Psychol Med Settings. 2010;17(3):230-7.

6. Baía I, Amorima M, Silva S, Kelly-Irving M, et al. Parenting very preterm infants and stress in Neonatal Intensive Care Units. Early Hum Dev. 2016;101:3-9.

7. Wormald F, Tapia JL, Torres G, Cánepa P, et al. Estrés en padres de recién nacidos prematuros de muy bajo peso hospitalizados en unidades de cuidados intensivos neonatales. Estudio multicéntrico. Arch Argent Pediatr. 2015;113(4):303-9.

8. Kaaresen PI, Rønning JA, Ulvund SE, Dahl LB. A Randomized, Controlled Trial of the Effectiveness of an Early-Intervention Program in Reducing Parenting Stress After Preterm Birth. Pediatrics. 2006;118(1):e9-19.

9. Shaw RJ, St John N, Lilo EA, Jo B, et al. Prevention of traumatic stress in mothers with preterm infants: a randomized controlled trial. Pediatrics. 2013;132(4):e886-94.

10. Hughes MA, McCollum J. Neonatal intensive care: mothers' and fathers' perceptions of what is stressful. J Early Interv. 1994;18(3):258-68.

11. Foa EB, McLean CP, Zang Y, Rosenfield D, et al. Effect of prolonged exposure therapy delivered over 2 weeks vs 8 weeks vs present-centered therapy on PTST symptom severity in military personnel: a randomized clinical trial. JAMA. 2018;319(4):354-64.

12. Feeley N, Zelkowitz P, Cormier C, Charbonneau L, et al. Posttraumatic stress among mothers of very lowbirth weight infants at 6 months after discharge from the neonatal intensive care unit. Appl Nurs Res. 2011;24(2):114-7.

13. Åhlund S, Clarke P, Hill J, Thalange NK. Post-traumatic stress symptoms in mothers of very low birth weight infants 2-3 years post-partum. Arch Womens Ment Health. 2009;12(4):261-4.

14. Holditch-Davis D, Bartlett T R, Blickman AL, Miles MS. Posttraumatic Stress Symptoms in Mothers of Premature Infants. J Obstet Gynecol Neonatal Nurs. 2003;32(2):161-71.

15. Kersting A, Dorsch M, Wesselmann U, Lüdorff K, et al. Maternal posttraumatic stress response after the birth of a very low-birth-weight infant. J Psychosom Res. 2004;57(5):473-6.

16. Karatzias T, Chouliara Z, Maxton F, Freer Y, Power K. Post-traumatic symptomatology in parents with premature infants: A systematic review of the literature. J Prenat Perinat Psychol Health. 2007;21(3):249-60.

17. Gondwe KW, Holditch-Davis D. Posttraumatic stress symptoms in mothers of preterm infants. Int J Afr Nurs Sci. 2015;3:8-17.

18. Greene MM, Rossman B, Patra K, Kratovil AL, et al. Depression, anxiety, and perinatal-specific posttraumatic distress in mothers of very low birth weight infants in the neonatal intensive care unit. J Dev Behav Pediatr. 2015;36(5):362-70.

19. Gray PH, Edwards DM, Gibbons K. Parenting stress trajectories in mothers of very preterm infants to 2 years. Arch Dis Child Fetal Neonatal Ed. 2018;103(1):F43-8.

20. Petit AC, Eutrope J, Thierry A, Bednarek N, et al. Mother's emotional and posttraumatic reactions after a pretermbirth: the mother-infant interaction is at stake 12 months after birth. PLoS One. 2016;11(3):e0151091.

21. Davidson JRT, Book SW, Colket JT, Tupler LA, et al. Assessment of a new self-rating scale for posttraumatic stress disorder. Psychol Med. 1997;27(1):153-60.

22. Bobes J, Calcedo-Barra A, García M, François M, et al. 
Evaluación de las propiedades psicométricas de la versión española de cinco cuestionarios para la evaluación del trastorno de estrés postraumático. Actas Esp Psiquiatr. 2000;28(4):207-18.

23. Holditch-Davis D, Santos H, Levy J, White-Traut R, et al. Patterns of psychological distress in mothers of preterm infants. Infant Behav Dev. 2015;41:154-63.
24. Hoge C, Chart K. A window into the evolution of traumafocused psychotherapies for posttraumatic stress disorder. JAMA. 2018;319(4):343-5.

25. Markowitz JC, Petkova E, Neria Y, Van Meter PE, et al. Is exposure necessary? a randomized clinical trial of interpersonal psychotherapy for PTSD. Am J Psychiatry. 2015;172(5):430-40. 


\section{ANNEX}

\section{Davidson Trauma Scale}

(Jonathan R. T. Davidson)

Translated into Spanish by: J Bobes, MT Bascarán, MP González, M Bousoño, A Calcedo, JA Hormaechea, D H. Wallace, February $17^{\text {th }}, 1999$.

Name:

Marital status: Age: Sex: M F

Date:

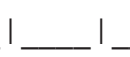

1. Have you had painful images, memories or thoughts of the event?

2. Have you had distressing dreams of the event?

3. Have you felt as though the event was re-occurring? Was it as if you were reliving it?

4. Have you been upset by something which reminded you of the event?.....

5. Have you been physically upset by reminders of the event? (This includes sweating, trembling, racing heart, shortness of breath, nausea, or diarrhea).

6. Have you been avoiding any thoughts or feelings about the event?

7. Have you been avoiding doing things or going into situations which remind you about the event?

8. Have you found yourself unable to recall important parts of the event?

9. Have you had difficulty enjoying things?

10. Have you felt distant or cut off from other people?

11. Have you been unable to have sad or loving feelings?

12. Have you found it hard to imagine having a long-life span fulfilling your goals?

13. Have you had trouble falling asleep or staying asleep?

14. Have you been irritable or had outbursts of anger?

15. Have you had difficulty concentrating?

16. Have you felt on edge, been easily distracted or had to stay "on guard"?

17. Have you been jumpy or easily startled?

Please identify the trauma that is most disturbing to you. 